\title{
A GROWING GLOBAL BURDEN
}

Stroke is a major public-health problem that tends to affect poorer countries more and leaves richer countries with ballooning medical costs. Yet it is often preventable. By Zoë Corbyn.

\section{ROOTS OF STROKE}

A stroke occurs when blood flow to the brain is interrupted, either by a blockage or a burst vessel. Without oxygen-rich blood,

the brain cells die and damage starts to show in the parts of the body controlled by those cells.

\section{Frontal lobe}

Controls movement, personality, behaviour, language, decision-making and short-term memory. A stroke in the right hemisphere affects movement in the left side of the body, and vice versa.

\section{OUT OF CONTROL}

Haemorrhagic stroke presents less of a burden in high-income countries because they tend to have better control over high blood pressure, a dominant risk factor for this type of stroke.

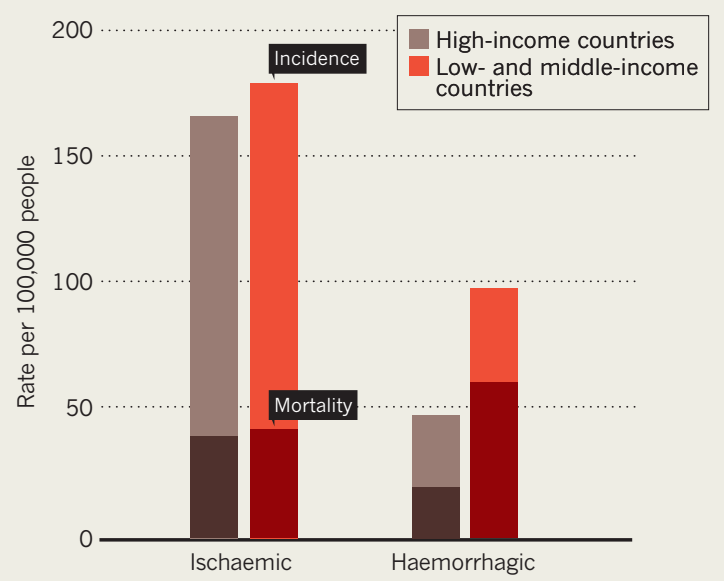

\section{LIFESTYLE CHOICES}

Some risk factors cannot be controlled, such as age, sex and ethnicity. However, ten factors are collectively associated with nearly $90 \%$ of the burden, and all can be mitigated.

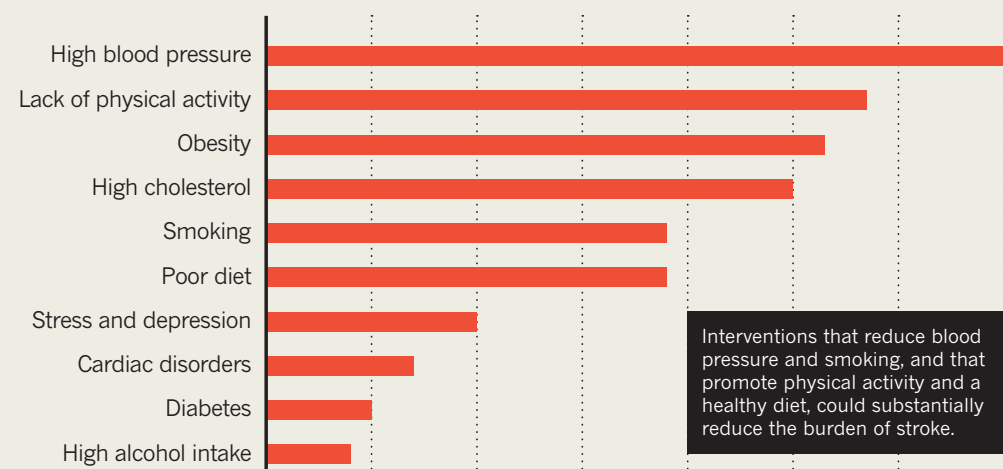

10 15 20

\section{Haemorrhagic stroke}

Occurs when a blood vessel bursts in the brain.

It is less common than ischaemic stroke but

more likely to be fatal. It often results from uncontrolled hypertension, and the only

treatment is surgery to stop the bleeding, relieve pressure and bypass the ruptured vessel.

\footnotetext{
Percentage of strokes attributable to risk factor
} 


\section{DEADLY TRENDS}

Stroke is responsible for roughly one-tenth of deaths, making it the second most common cause after heart disease worldwide. Death rates are highest in Eastern Europe, Russia and southeast Asia, regions that tend to lack specialized health services for treatment.

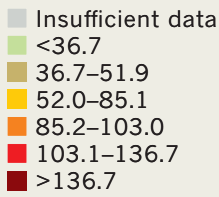

Age-adjusted deaths in 2010 per 100,000 people. Data presented by region.

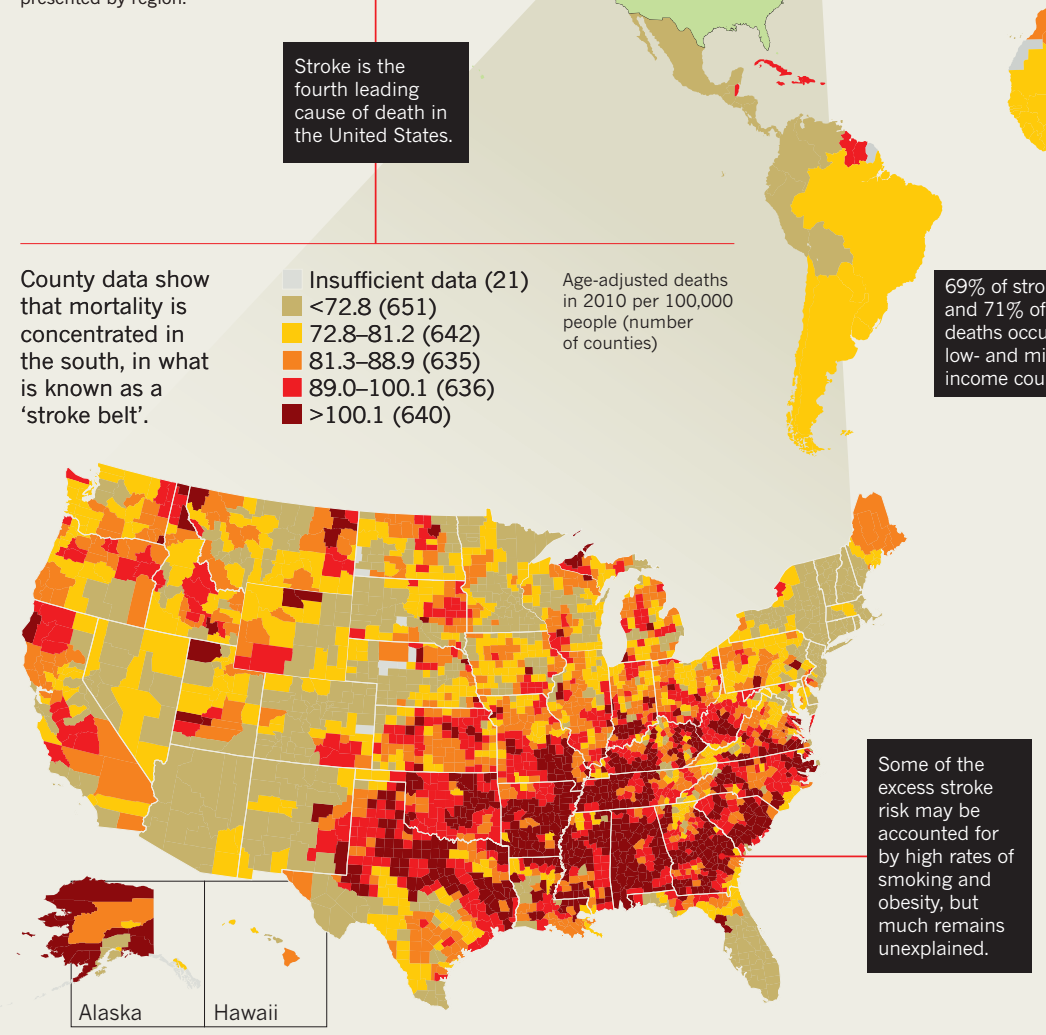

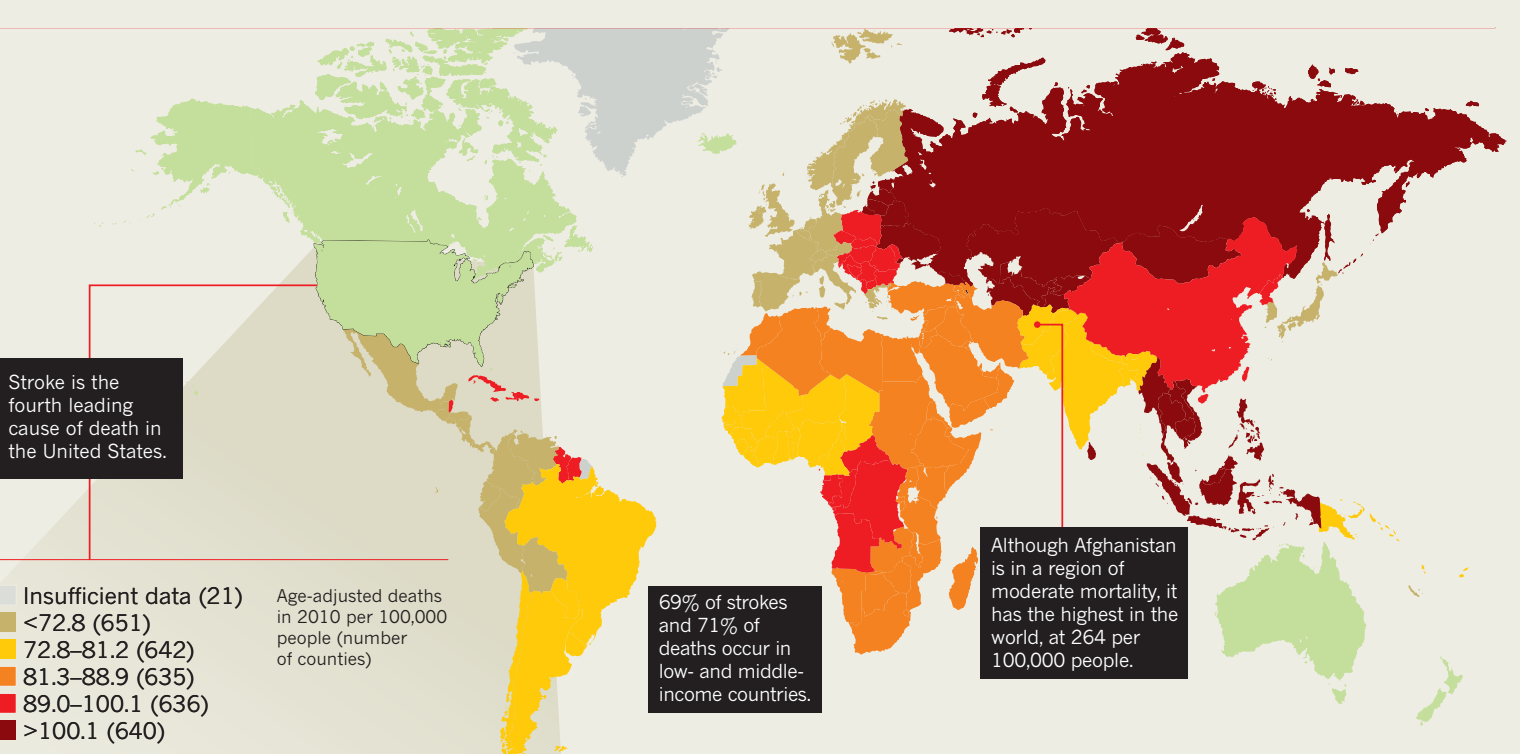

\section{AGE CONCERN}

Both incidence and mortality are falling in high-income countries. But prevalence is rising, particularly in high-income nations.

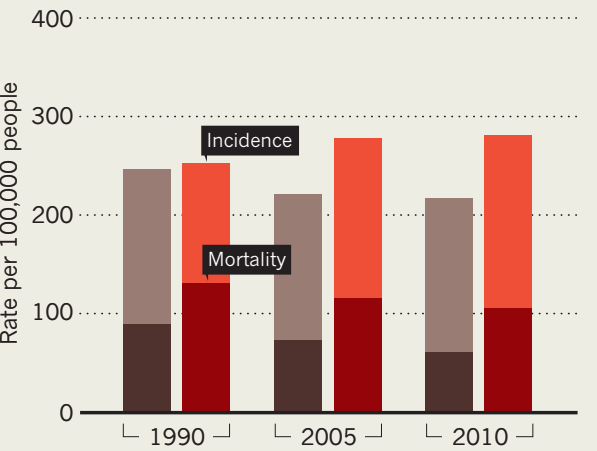

High-income countries

Low- and middle-income countries

800

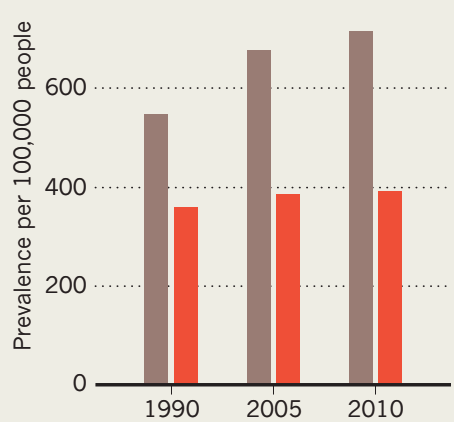

\section{FINANCIAL TIMES}

Direct medical costs are expected to rise substantially in the United States because prevalence will increase as the population ages.

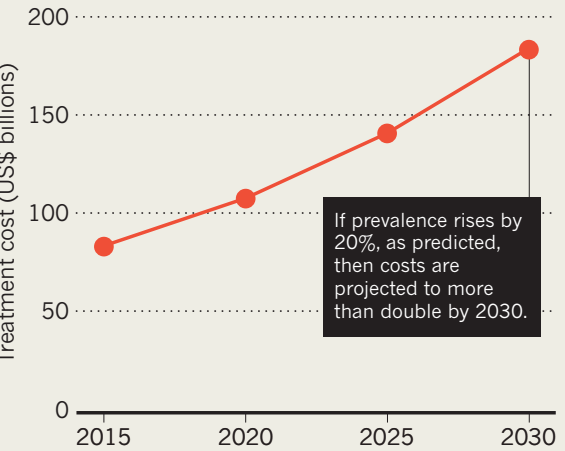

Sources: Out of control: R. V. Krishnamurthi et al. Lancet Glob. Health 1, e259-e281 (2013). Lifestyle choices: M. J. O'Donnell, et al. Lancet 376, 112-123 (2010). Deadly trends and Age concern: V. L. Feigin et al. Lancet 383, 245-255 (2014); World Health Organization; US Centers for Disease Control and Prevention. Financial times: B. Ovbiagele et al. Stroke 44, 2361-2375 (2013). 